\title{
Quality of working life of dental office staff: Surveys of work of dental assistants in Senegal
}

\author{
Soumboundou Sankoung ${ }^{1, *}$, Khalifa Dieng ${ }^{2}$, Mamadou Lamine Ndiaye ${ }^{3}$, Lamine Sane ${ }^{4}$, Babacar Toure ${ }^{5}$ \\ ${ }^{1-3}$ Doctor, ${ }^{4,5}$ Assistant Professor, ${ }^{1,-3,5}$ Dept. of Pharmacy and Odontology, Faculty of Medicine, University of Dakar, Senegal, \\ ${ }^{4}$ Hospital Center University Aristide Le Dantec, Dakar, Senegal
}

*Corresponding Author:

Email: aladjiba12@gmail.com

\begin{abstract}
The working conditions are a set of parameters that influence the satisfaction found daily at this activity. Dental assistants play an invaluable part in the dental team by improving the dentist's efficiency in delivering oral health care and by increasingly influencing the productivity of the dental office through interpersonal relationships and competence these techniques. The purpose of this study was to evaluate the working conditions and to determine the degree of satisfaction.

Material and Methods: This descriptive and cross-sectional study was conducted with dental assistants listed in the registries of the Association of Dental Assistants of Senegal. This is a self-administered survey with a three-part form.

The study lasted two months and the 140 participants were informed of the nature and purpose of the survey and their participation was anonymous and voluntary.

A total of 113 responded to the questionnaire, data was collected and analyzed with SPSS 18 for Windows (SPSS Inc., Chicago, Illinois, USA).

The comparison of the data was made with the chi-square tests X2 and Pearson and a significance threshold $\mathrm{p} \leq 0.05$ was retained.

Results: The results of this study conducted with Senegalese dental assistants show very precarious working conditions resulting in low salary levels; $53.1 \%$ earn less than 200 euros for 40 hours of work per week and $46 \%$ work without a contract. Despite a very stressful work environment, a statistically significant difference could not be established between salary and job satisfaction. Conclusion: The results of this study show a precarious profession with very low pay levels and almost non-existent work contracts.
\end{abstract}

Keywords: Working conditions, Remuneration, Stress, Dental assistant, Dentistry.

\section{Introduction}

Working conditions are a set of parameters that affect the daily satisfaction of an activity. ${ }^{1,2}$ Those of health personnel are generally dependent on the intensity of physical effort and the environment in which they work.

In the dental field, the care team is made up of dental surgeons, hygienists and dental assistants.

Dental assistants play an invaluable part in the dental team by improving the dentist's efficiency in delivering oral health care and by increasingly influencing the productivity of the dental office through interpersonal and interpersonal relationships technical skills. ${ }^{3}$ In Senegal and other African countries, dental assistants work most often full-time and play many roles in dental practices: receptionist, radiology technician or dental educator.

In the United States and Europe, assistants can have expanded functions that allow them to do many additional tasks related to care.

However, although the medical literature on the working conditions of health workers is vast, there is almost no research in this area concerning workers in the oral health sector in Senegal, especially dental assistants.

The purpose of this study was to evaluate the working conditions, the characteristics of the job and to determine the degree of satisfaction.

\section{Material and Methods}

This descriptive and cross-sectional study was carried out among the dental assistants listed in the registries of the association of dental assistants of Senegal. This is a self-administered survey that includes three sections:

The first concerns socio-demographic data age sex level of schooling, marital status, level of education.

The second part deals with the working environment and the rates of remuneration and finally a third part about the level of satisfaction and relationships in the dental team.

The study lasted two months and the 140 participants were informed of the nature and purpose of the survey and their participation was anonymous and voluntary.

A total of 113 responded to the questionnaire, the data were collected and analyzed with SPSS software. The qualitative variables are expressed on average and the quantitative variables in percentage.

The comparison of the data was made with the chi-square tests $\mathrm{X}^{2}$ and Pearson and a significance threshold $\mathrm{p} \leq 0.05$ was retained.

\section{Results}

A total of 113 out of 140 responded to the questionnaire, which corresponds to a participation rate of $89 \%$. Our sample is largely dominated by women who represent $69 \%$ against $31 \%$ for men. $45 \%$ of participants were married, of which $43.4 \%$ had more than one year of 
experience (Table 1). The level of education was quite high because more than half had validated their high school diploma, 38.4\% +/- 4.5 had obtained the baccalaureate (Table 2).

The salary threshold seems too low, $53.1 \%$ earn between 50000 (75 €) and 100000 CFA (176€) per month is less than $200 €$ and only $5.3 \%$ have a salary higher than $176 €$.

Almost half of the participants work without a contract, $15 \%$ work under permanent contracts (CDI) and only $13.3 \%$ contribute for the retirement pension.
The contract of employment seems strongly linked to the remuneration because those who have obtained a Cdi or Cdd contract have wages higher than $150 €(\mathrm{p} \leq 0.009)$

But the working time has no added value on the remuneration indeed those who are without a contract work more than 40 hours a week, whereas those who work in IDC work most often between 16 and 25 hours and have the highest pay (Fig. 1).

Table 1: Demographic Parameters

\begin{tabular}{|l|c|c|}
\hline $\begin{array}{l}\text { Socio-demographic variables } \\
\text { Gender }\end{array}$ & N & \% \\
\hline Male & 35 & 31 \\
\hline Female & 78 & 69 \\
\hline Marital status & & \\
\hline Maries & 63 & 55.8 \\
\hline Singles & 50 & 44.2 \\
\hline Study level & & \\
\hline High school & 46 & 40.7 \\
\hline Bachelor & 44 & 38.9 \\
\hline Secondary school & 14 & 12.4 \\
\hline No study & 9 & 8 \\
\hline number of years of experience & & \\
\hline$\leq 1$ year & 15 & 13.3 \\
\hline 1-5 years & 49 & 43.4 \\
5-10 years & 28 & 24.8 \\
$\geq 10$ ans & 11 & 18.6 \\
\hline
\end{tabular}

Table 2: Compensation by type of contract

\begin{tabular}{|l|c|c|c|c|c|}
\hline \multirow{2}{*}{ Contracts } & \multicolumn{3}{|c|}{ Renumeration } & \multirow{2}{*}{ Total } & P-value \\
\cline { 2 - 5 } & $\begin{array}{c}76 € \\
\mathrm{n}(\%)\end{array}$ & $\begin{array}{c}76-150 € \\
\mathrm{n}(\%)\end{array}$ & $\begin{array}{c}150-300 € \\
\mathrm{n}(\%)\end{array}$ & & \\
\hline No contracts & $35(66)$ & $18(34)$ & - & $53 \%$ & \\
\cline { 1 - 5 } $\begin{array}{l}\text { Contract duration } \\
\text { déterminer }\end{array}$ & $17(39,5)$ & $23(53,5)$ & $3(7,0)$ & $43 \%$ & \\
\hline $\begin{array}{l}\text { Contract indefinite } \\
\text { duration }\end{array}$ & $8(47,1)$ & $6(35,3)$ & $3(17,6)$ & $17 \%$ & \multirow{2}{*}{0,009} \\
\hline Total & $60(53,1)$ & $47(41,6)$ & $6(5,3)$ & 113 & \\
\hline
\end{tabular}

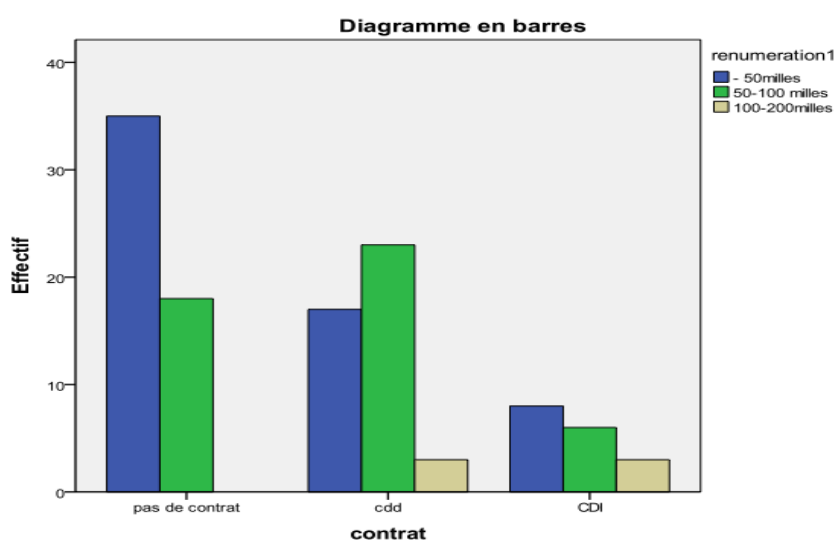

Fig. 1: Remuneration according to the type of contract 


\section{Discussion}

On the basis of data obtained from the association, the results of this study seem to be quite representative of dental assistants in Senegal. A profession largely dominated by women, as confirmed by recent studies. ${ }^{3}$

Now a days, to be a qualified dental assistant everywhere else in the world, it is necessary to justify training. In Senegal, dental assistants cannot work directly in the patient's mouth. Stains such as taking Xrays, removing sutures, topical applications of anesthetics, and sealing furrows or cavities with prevention materials and prescribing prescriptions are not normally allowed.

In Brazil, according to the study by Nelson Rubens et $\mathrm{al}^{4}$ the same situation prevails for dental assistants, however dental hygienists are authorized to perform these proscribed activities for assistants. In this study most assistants perform additional tasks that are not allowed. Thus $30.4 \%$ of them participate in the drafting of the ordinances. Now in medicine the prescription constitutes the writing which contains the prescription of the doctor intended for a patient. This prescription subject to strict regulations seems overused and held with lightness.
In France the public health code is formal in stating that the dental assistant cannot in any way substitute the person of the dental surgeon for the prerogatives attached to the diploma of dentist. This study shows a satisfactory level of education because more than half of the participants have obtained the secondary school diploma and $38.9 \%$ are in possession of the baccalaureate.

Unlike Brazil or primary education is a requirement for all dental assistants and dental hygienists must demonstrate a secondary curriculum, this study shows that $8 \%$ of assistant were not attending school. ${ }^{3}$ This high level of education is a sign of progress and social success because it is known that a low level of education has effects on wages and that a high level predisposes the individual to develop an intelligent practice, to articulate and mobilize knowledge and skills. However in this study, the measure 'association between salary level and schooling does not show a significant difference.

The salary seems to be more related to the type of contract because the high pay is observed for those who benefit from indefinite contract (cdi) and determined (cdd). Working time does not affect pay as even those who work more than 40 hours have low wages (Fig. 2).

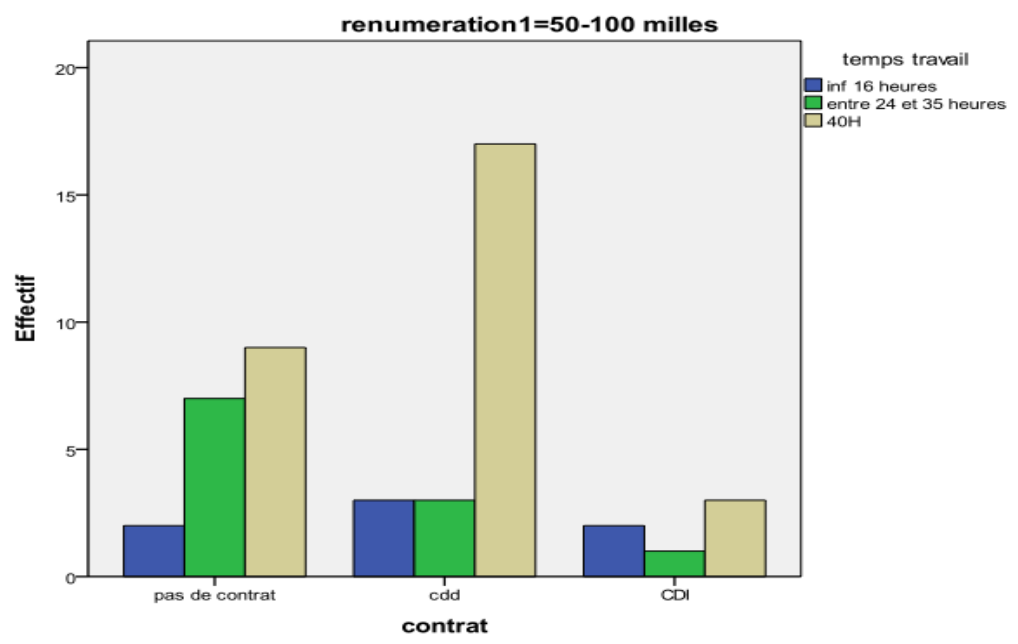

Fig. 2: Working time according to type of contract

These results are different from those of the study by Khader and Abu Sharbain ${ }^{5}$ who show in their study of dental assistants in Jordani, higher salary levels than those of this sample because $26.8 \%$ earn 200 JD / $240 €$ and $45.5 \%$ work at least 8 hours a day. In the USA between 2009 and 2013 assistants work on average 34 hours a week for an annual fee of 36,260 dollars to 17.34 dollars per hour 6. In Brazil, Nelson Rubens et al ${ }^{4}$ report in their study salary levels higher than those of our study sample with an average salary of $160 €$ but lower than the average salary perceived by a French dental assistant who is $1.500 €$. In the US the average salary varies according to the states; it is 960 in the state of Puerto Rico while in Oregon it is 2056 US dollar according to the Bureau of Labor Statistics. ${ }^{7.8}$ Satisfaction at work is an attitude that an employee develops at his workplace and this is translated by a jovial spirit, an overflowing enthusiasm and a certain rigor to the task. The factors contributing to this state are multiple and change over time. Indeed, when people feel that their wages are not fair or that working conditions are bad or that the benefits are insufficient, they feel dissatisfied with their work. In this study, $53.2 \%$ of participants felt their work was stressful, $23.4 \%$ had once lost their job and only $13.5 \%$ had a pension contribution. A significant difference could not be established between this stressful environment and low salary levels. Far from these precarious conditions 
do not seem to alter the dentist-assistant relationship, because most of the assistants claim to have good rapport with the health care team, particularly with the dentist, and that the dentist shows respect and kindness to the dentist in their respect. However this contrast does not mean that these assistants feel satisfied or dissatisfied with their work.

Locker et $\mathrm{al}^{9}$ shows that the main sources of dissatisfaction for dental assistants were low income, lack of professional development opportunity and lack of recognition. In their study, nearly one in five respondents scored on a standard measure of emotional distress, indicating that there is cause for concern.

Work stress has proven to be a significant predictor of job satisfaction. Similarly, stress and job satisfaction have emerged as important signals of emotional wellbeing. On the other hand, the ambiguity of the role of assistant, the underutilization of skills and low selfesteem have emerged as major problems..$^{9-11}$

These observations from the work of Locker et $\mathrm{al}^{9}$ are theoretically interesting in this respect. They have implications for the organization of dental practice in order to limit the burn-out phenomena reported in several studies of health workers. The study of Le Gall $\mathrm{jr}$ et $\mathrm{al}^{12}$ performed in an intensive care unit in Paris shows that the phenomenon of burnout burn out would be present in half of the intensive care physicians and that this syndrome would be linked to a large number of hours of work.

\section{Conclusion}

The results of this study show a precarious profession with very low wages and unsatisfactory working conditions. This study may be of interest to dentists, care staff and legislators who are concerned with how salary levels may affect the working conditions of dental assistants but also and above all their quality of life.

\section{Acknowledgements}

The authors wish to thank the dental assistants who assisted with the study and Lamine Sane for collecting the data.
Funding: No funding sources.

Conflict of interest: None declared.

\section{References}

1. International Labour Office. Psychosocial factors at work: recognition and control. Report of the Joint ILO/WHO Committee on Occupational Health - Ninth Session. Geneva: International Labour Office. 1984

2. Erdem R, Rahman S, Avci L et al. Investigating job satisfaction and burnout levels of the persons working for the Hospitals at City Center of Elazig, Turkey. J Appl Sci Res 2008;4:188-201.

3. Ersoy F, Edirne T, Yýldýrým RC. Vocational satisfaction of health personnel. IV National of Health and Hospital Management Symposium Book; 2001:382-387.

4. Gibbons DE, Corrigan M, Newton JT. A national survey of dental hygienists: working patterns and job satisfaction. Br Dent J 2001;190:207-10.

5. Nelson R ML, Caldas AF,Luiz Gutenberg T MC. Job satisfaction among dental assistants in Brazil Braz Dent $J$ 2013;24(1):53-8

6. Khader YS, Abu-Sharbain G. Dentist-assistant interaction styles in Jordan. Int J Dent Hyg 2009;7(2):131-35.

7. Bureau of Labor Statistics (BLS), Occupational Employment Statistics (OES), May 2014.

8. U.S. Bureau of the Census, American Community Survey, 2009-2013.

9. Bureau of Labor Statistics at https://data.bls.gov/oes/\#/home

10. Locker D. Work stress, job satisfaction and emotional well-being among Canadian dental assistants. Community Dent Oral Epidemiol 1996; 24:133-137.

11. 9. Peterson S. El odontólogo y su assistente. Buenos Aires: Mundi 1977;24-6.

12. Kamal Y, Hanif F. Pay and job satisfaction: a comparative analysis of different Pakistani commercial banks. MPRA, 2009:1-21.

13. Butters JM, Willis DO. Satisfaction level of dental office personnel. Gen Dent 1993;41:236-40.

14. Kruger E, Smith K, Tennant M. Dental therapy in Western Australia: profile and perceptions of the workforce. Aust Dent J 2006;51:6-10.

15. Le Gall JR ${ }^{1}$, Azoulay E, Embriaco N, Poncet MC, Pochard F. [Burn out syndrome among critical care workers Bull Acad Natl Med 2011;195(2):389-97.

16. Luzzi L, Spencer AJ, Jones K, Teusner D. Job satisfaction of registered dental practitioners. Aust Dent J 2005;50:179-85.

How to cite the article: Sankoung S., Dieng K., Ndiaye M., Sane L., Toure B. Quality of working life of dental office staff: Surveys of work of dental assistants in Senegal. Int Dent J Student's Res 2018;6(3):51-54. 